\title{
COMPETITIONS OF STUDENT PROJECTS AS AN IMPORTANT COMPONENT IN POLICY OF IMPLEMENTATION OF THE TRIPLE HELIX CONCEPT IN RUSSIA
}

\author{
Anton V. Pogrebnoi \\ Vasilii Yu. Rud \\ Maxim Pasholikov \\ Gennady Podolsky
}

St. Petersburg State Polytechnical University, Russia

\begin{abstract}
Saint-Petersburg's government in recent years implements many projects that work on the intersection of science, education and business in cooperation with the city administration. One of the projects implemented by youth in the STU was a competition of student projects, entitled "Laboratory of my dreams." At this competition student teams were able to show that the expert committee as they see a modern laboratory for teaching and research, which is fully equipped to perform complex and interesting problems. The prize was an obtaining of financing for the purchase of equipment required for laboratory, which is purchased by sources of the Ministry of Education and Science by the Program of National Research University SPbSPU and by city's sources. Projects submitted to the competition were different, but all have been aimed at creating important laboratory facilities for educational, scientific problems with the possibility of business applications. Noticeable part of the project was focused on solving environmental problems and environmental protection. One of the winners presented a project about the environment and improvement the efficiency of energy systems working with the processed products - "Efficiency research of the energy complex with direct using converter hydrogen (containing $\mathrm{CH} 42 \div 7 \%$ ) obtained from biogas of municipal solid waste (MSW) by methods of thermodynamics and electrochemical kinetics ". After the purchase of equipment, theoretical and experimental results will be the basis for radically new solutions and for the progress of perspective ways of producing fuel and electricity using energy-saving and energy-efficient technologies. All of these results may be very attractive to create new educational programs, international researches and innovative projects.
\end{abstract}

\section{KEYWORDS}

Triple Helix, competition, business, project, energy-saving, efficient, science, laboratory, modernization, administration, government, innovative business 


\section{INTRODUCTION.}

The Triple Helix concept comprises three basic elements:

- A more prominent role for the university in innovation, on a par with industry and government in a knowledge-based society

- A movement toward collaborative relationships among the three major institutional spheres, in which innovation policy is increasingly an outcome of interaction rather than a prescription from government

- In addition to fulfilling their traditional functions, each institutional sphere also "takes the role of the other" performing new roles as well as their traditional function. Institutions taking non-traditional roles are viewed as a major potential source of innovation in innovation.

The increased importance of knowledge and the role of the university in incubation of technology-based firms have given it a more prominent place in the institutional firmament [1]. Saint-Petersburg's government in recent years implements many projects that work on the intersection of science, education and business in cooperation with the city administration. One of the projects implemented by youth in the STU was a competition of student projects, entitled "Laboratory of my dreams."

\section{REVIEW OF «LABORATORY OF MY DREAMS».}

Modern equipment, latest design, unique devices, then what you just said, "If only we had such a ..." - now students have a real chance to get it all. Appearance of the laboratory depends on their imagination.

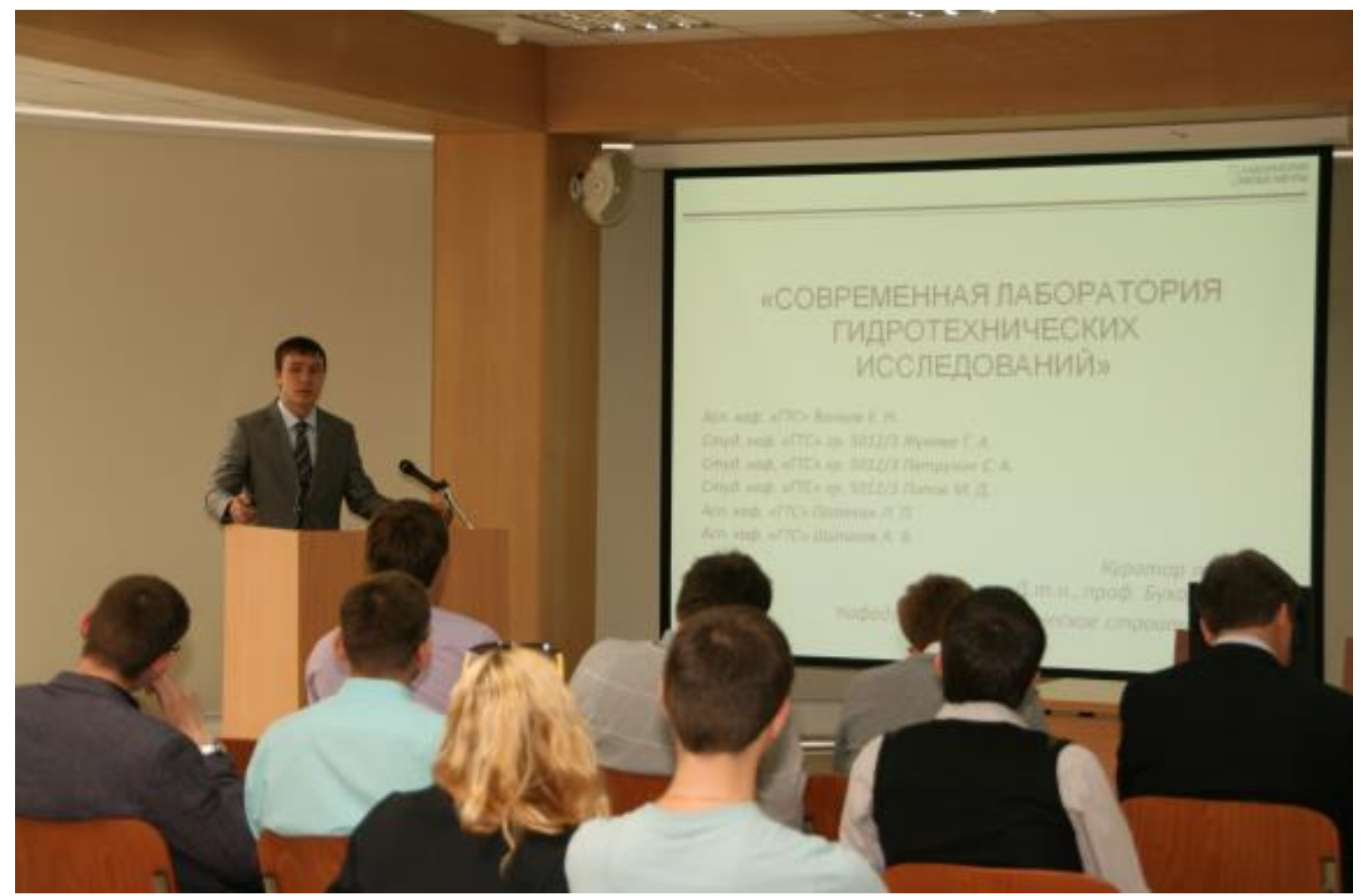

Figure 1. One of the teams presented a project about new laboratory of hydrotechnical research. 
The competition was held in the following areas:

1. The research activities of students;

2. Update logistics outdated laboratories;

3. Creating the training of students in the following areas: "Science", "Social" and "Information" [2].

At this competition student teams were able to show that the expert committee as they see a modern laboratory for teaching and research, which is fully equipped to perform complex and interesting problems. Projects aimed at improving the material and technical basis of the existing laboratories and the creation of entirely new conditions for students who wish to explore new scientific horizons! The competition included a provision that a student project could be profitable. This condition was not mandatory, but many projects were reflected strong economic review. Projects submitted to the competition were different, but all have been aimed at creating important laboratory facilities for educational, scientific problems with the possibility of business applications.

Noticeable part of the project was focused on solving environmental problems and environmental protection. One of the winners presented a project about the environment and improvement the efficiency of energy systems working with the processed products "Efficiency research of the energy complex with direct using converter hydrogen (containing CH4 $2 \div 7 \%$ ) obtained from biogas of municipal solid waste (MSW) by methods of thermodynamics and electrochemical kinetics ". After the purchase of equipment, theoretical and experimental results will be the basis for radically new solutions and for the progress of perspective ways of producing fuel and electricity using energy-saving and energy-efficient technologies. All of these results may be very attractive to create new educational programs, international researches and innovative projects.

Also student teams were presented the projects aimed at promoting science and technology, projects of the laboratory of scientific and technical creativity, etc. Of course, many of the participants made mistakes when applying for the competition. However, a large number of teams have been reasonable and innovative ideas are really important! Therefore, these commands will take a chance to take part in next time. Increasing experience with these activities in the universities will be able to restore and improve the activity of the students in their research and development of innovative products. Of the thirty-five of the projects submitted to the competition in the second round were only 13 teams. In the second round jury selected six teams from all applicants for victory. The prize was an obtaining of financing for the purchase of equipment required for laboratory, which is purchased by sources of the Ministry of Education and Science by the Program of National Research University SPbSPU and by city's sources (see Figure 2). 


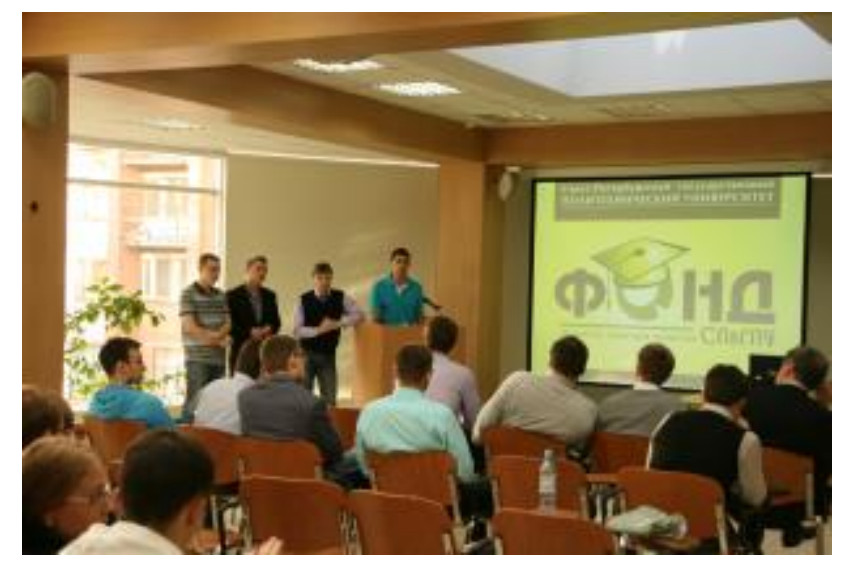

Figure 2. All money prizes were from National Research University SPbSPU Fund.

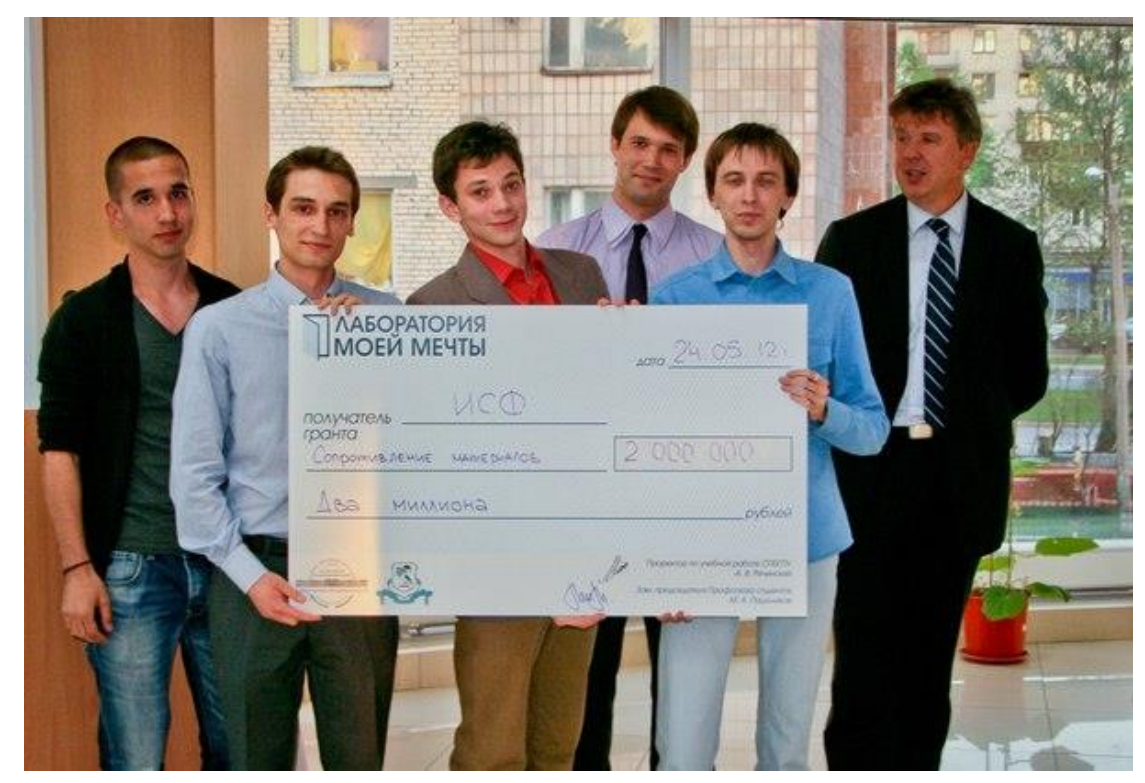

Figure 3. Winners of the competition with their money prize for purchase of equipment. Organizers (from right to left): Alexander Rechinsky (first), Gennady Podolsky (third).

\section{CONCLUSION}

Creating the conditions for study and work - one of the most important tasks of modernization in higher education. Students are a unique class of people who are ready for the most ambitious goals. Students and youth - the hope of every country to a long and successful prosperity in science and technology. Therefore, support for the competitions of student projects is a priority in the implementation of programs for Youth policy in Russia. Support for such projects at universities provides quality dialogue between students and faculty. Students offer a wide variety of conditions in which they would like to conduct research and they show the administration real requirements of the necessary equipment. Many laboratories need to retool and sometimes to reorient research for the development at new interdisciplinary areas of science. Such competitions as this contributes to the objectives of the concept triple helix in St. Petersburg and in Russia. Stimulating appearance of new business ideas needed to solve the problems of the modern world (environmental, economic, 
social, etc.) is not possible without the involvement of students and young people in competitive conditions. All of government's power have to be aimed to create multiple system of influx of young people in science, education and high technology and to create a system repair mechanisms of scientific and scientific-educational staff.

Because of competitions organized with the direct participation of student organizations, the development of competition of student projects will strengthen the position of leadership among active student societies in universities. In future, this will lead to young qualified experts in innovative business environment that will provide quality and selection of projects submitted to the competition, as well as gaining experience for most students. That experience is required in order that in the future Russia became the owner of highly qualified personnel.

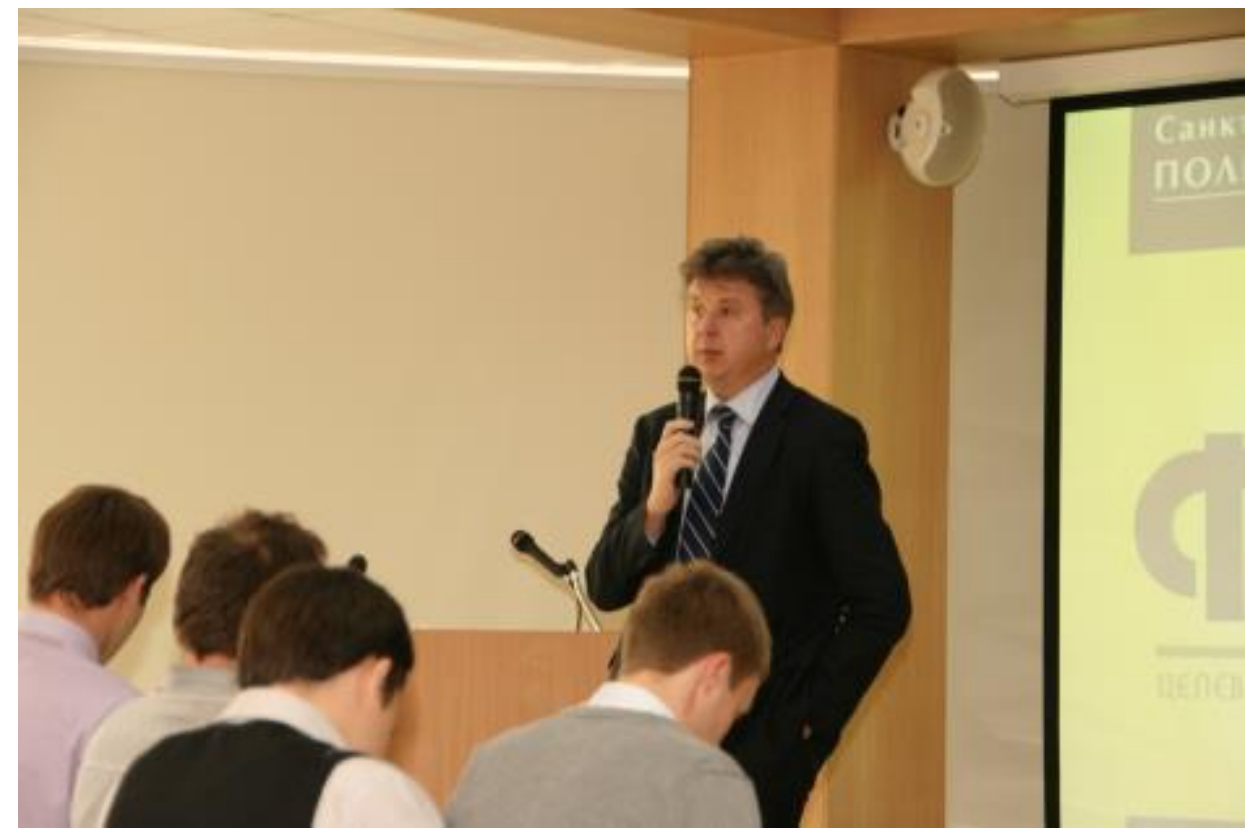

Figure 3. Vice rector of study of SPbSTU Alexander Rechinsky has been talking about majority of such kind of competitions.

\section{REFERENCES}

[1] Theoretical framework «Triple helix». Materials of Triple Helix IX International Conference "Silicon Valley: Global Model or Unique Anomaly?"11-14 July 2011; http://www.triplehelixconference.org/

[2] The Federal Program "Scientific and scientific-pedagogical personnel of innovative Russia"in 2009-2013.

http://www.youngscience.ru/pages/main/documents/fcp/5100/index.shtml (in russian). 